\title{
Biological, Electronic, and Functional Thin Films
}

\author{
ROGER NARAYAN ${ }^{1,2}$ \\ 1.-University of North Carolina and North Carolina State University, Raleigh, NC, USA. \\ 2.-e-mail: roger_narayan@msn.com
}

Processing of thin films has a long and extensive history; techniques such as electroplating, sputtering, and thermal evaporation date to the nineteenth century. ${ }^{1,2}$ As noted by Van Hove, the large and growing field of nanoscience evolved from the field of surface science over the past half century. ${ }^{3}$ In recent years, thin film development for nanoelectronic devices, optoelectronic devices, thermoelectric devices, batteries, sensors, wearable devices, implantable devices, and water purification membranes has generated significant interest. ${ }^{4-9}$ New technologies, including roll-to-roll processing, are being developed that will enable thin film processing at lower cost than conventional methods. ${ }^{10}$

In this special topic, efforts by several leading researchers to develop thin films for biological, electronic, and functional thin films are considered. For example, in their article "Processing for Highly Emissive CZ-Silicon by Depositing Stressed Sol-Gel Films," S. Abedrabbo, A.T. Fiory, and N.M. Ravindra discuss the use of an inexpensive sol-gel approach to create erbium-doped silicon oxide coatings for optical applications. El Mostafa Benchafia, Chi Yu, Marek Sosnowski, N.M. Ravindra, and Zafar Iqbal, in their paper titled "Plasma Synthesis of Nitrogen Clusters on Carbon Nanotube Sheets," used a radio-frequency plasma synthesis approach based on plasma-enhanced chemical vapor deposition for growth of polymeric nitrogen clusters on carbon nanotube sheets and nanopaper. The paper titled "Electrical Resistance Decrease Due to Grain Coarsening under Cyclic Deformation” by O. Glushko and M.J. Cordill examines electron beam-evaporated copper films on polyimide substrates under cyclic tensile loading and associated a reduction in electrical resistance in these materials with room-temperature, strain-induced grain coarsening. Robert A. Hall, Steven M. George,
Yeongae Kim, Woonbong Hwang, Meghan E. Samberg, Nancy A. Monteiro-Riviere, and Roger J. Narayan, in their paper titled "Growth of Zircone on Nanoporous Alumina Using Molecular Layer Deposition," examine the growth of skin cells on nanoporous alumina that was coated with a zirconiumcontaining hybrid organic/inorganic polymer. Sarang V. Muley and Nuggehalli M. Ravindra review in their paper "Emissivity of Electronic Materials, Coatings, and Structures" the optical properties of several types of single-component and multilayered materials. A.M. Oladoye, J.G. Carton, and A.G. Olabi describe the use of a modified micro-blasting process known as CoBlast $^{\mathrm{TM}}$ for depositing graphite-containing coatings on stainless steel and titanium substrates in their paper "Characterization of Graphite Coatings Produced by CoBlast ${ }^{\mathrm{TM}}$ Technology." These coatings have potential corrosion and tribological applications. The paper titled "Graphene: The Thinnest Known Coating for Corrosion Protection" by R.K. Singh and Abhishek Tiwari considers the use of graphene as a corrosionresistant coating for metals and metal alloys, while James Winnett and Kajal K. Mallick discuss the use of an adaptive foam reticulation approach to create porous scaffolds out of titanium and titanium- $6 \%$ aluminum-4\% vanadium alloy in their paper titled "Parametric Characterization of Porous 3D Bioscaffolds Fabricated by an Adaptive Foam Reticulation Technique."

We would like to thank Shirley Litzinger and Maureen Byko for their tireless efforts to make the "Biological, Electronic, and Functional Thin Films" special topic possible. We hope that this topic contributes to an improved understanding of thin film science and signifies the major role of The Minerals, Metals \& Materials Society in dissemination of information on thin films and other functional materials.

\section{REFERENCES}

1. A. Lakhtakia and R. Messier, in Sculptured Thin Films: Nanoengineered Morphology and Optics (SPIE Press Monograph Vol. PM 143) (SPIE Publications, Bellingham, WA, 2005), pp. 27-48. 
2. Thin Film Deposition Technologies. http://www.ieeeghn org/wiki/index.php/Thin_Film_Deposition_Technologies.

3. M.A. Van Hove, Catal. Today 113, 133 (2006).

4. M.G. Buonomenna, Desalination 314, 73 (2013).

5. C. Pang, C. Lee, and K.Y.Suh, J.Appl. Polym. Sci. 130, 1429 (2013).

6. Q.H. Wang, K. Kalantar-Zadeh, A. Kis, J.N. Coleman, and M.S. Strano, Nat. Nanotechnol. 7, 699 (2012).
7. R. Moos, N. Izu, F. Rettig, S. Reiss, W. Shin, and I. Matsubara, Sensors 11, 3439 (2011).

8. A. Patil, V. Patil, D.W. Shin, J.W. Choi, D.S. Paik, and S.J. Yoon, Mater. Res. Bull. 43, 1913 (2008).

9. A. Roncaglia and M. Ferri, Sci. Adv. Mater. 3, 401 (2011).

10. G.M. Hanket, R.W. Birkmire, S.C. Jackson, and R.E. Rocheleau, Ind. Eng. Chem. Res. 48, 5923 (2009). 